\title{
Diurnal variation and vertical distribution of carbonaceous aerosols in the southern part of Thailand
}

\author{
S. Pongpiachan ${ }^{1}$, S. Pongnailert ${ }^{1}, \mathrm{~K} . \mathrm{F} . \mathrm{Ho}^{2} \& \mathrm{~J} . \mathrm{Cao}^{2}$ \\ ${ }^{I}$ NIDA Centre for Research and Development of Disaster Prevention \\ and Management, School of Social \& Environmental Development, \\ National Institute of Development Administration, Thailand \\ ${ }^{2}$ SKLLQG, Institute of Earth Environment, \\ Chinese Academy of Sciences (IEECAS), China
}

\begin{abstract}
Carbonaceous compositions, water-soluble ionic species and trace gaseous species were identified and quantified in Hat-Yai city, Thailand. All samples were collected every three hours consecutively from 21:00 $\mathrm{h}$ December $17^{\text {th }}$ to 21:00 h December $20^{\text {th }}$ at Site $1(30 \mathrm{~m} \mathrm{agl})$, Site $2(60 \mathrm{~m} \mathrm{agl})$ and Site 3 (125 m agl). The averaged concentration of OC was significantly higher at Site 1 than those detected at Site 2 and Site 3 suggesting that anthropogenic activities at ground level might play a major role in governing air quality at ground level. The main objective of this study is to investigate the vertical distribution of carbonaceous aerosols in Hat-Yai's atmosphere for the first time by using IMPROVE TOC (Interagency Monitoring to Protect Visual Environments Total Organic Carbon) protocol. The morning peak of carbonaceous compositions observed during the sampling period of 06:00-09:00 emphasized the main contribution of traffic emissions on OC/EC contents in Hat-Yai city. In this study, we found that aged maritime aerosols from long-range transportation and/or biomass burning particles overwhelmed carbonaceous aerosols at the top of building. Whilst hierarchical cluster analysis and Pearson correlation analysis show some considerable influences of night-time tourism activities on carbonaceous contents at ground level, principal component analysis highlights
\end{abstract}


the impacts of maritime aerosols, biomass burning and possibly agricultural waster burning particles at a higher atmospheric layer.

Keywords: carbonaceous aerosols, vertical distribution, tropical climate, principal component analysis, hierarchical cluster analysis.

\section{Introduction}

Carbonaceous aerosols, generally recognized as organic carbon (OC) and elemental carbon (EC) particles, have been intensively studied in the past decades because these atmospheric particles offer a wide range of impacts on both health and climate system [1,2]. Carbonaceous aerosol is detrimental to human health, according to recent study on effects of fine carbonaceous particles containing high and low unpaired electron spin densities on lungs of female mice [3]. As a consequence of concern over their existence in the atmospheric environment, several studies were conducted to investigate its influences on fate of carcinogenic and/or mutagenic substances such as polycyclic aromatic hydrocarbons (PAHs), polychlorinated biphenyls (PCBs), polychlorinated dibenzo- $p$-dioxins and dibenzofurans $(\mathrm{PCDD} / \mathrm{Fs})$ and pesticides [4-8]. These carbon-containing compounds are often referred to as persistent organic pollutants (POPs) that are persistent to photochemical degradation, biological decomposition, and chemical reactions [9].

According to circumstances, there have been a growing number of studies focusing on the analysis of chemical compositions of carbonaceous aerosols collected at observatory sites around the world [10-13]. During the last decade, more studies are concentrating on the application of $\mathrm{OC} / \mathrm{EC}$ ratio as an indicator of primary and secondary carbonaceous particles [14-16]. In spite of the presence of numerous scientific publications regarding the diurnal variation of carbonaceous aerosols, only a limited number of studies have been undertaken to simulate the vertical distribution of particulate $\mathrm{OC} / \mathrm{EC}$ in the urban atmosphere [1]. Furthermore, the knowledge of OC/EC compositions in tropical aerosols is extremely rare. According to our best knowledge, there are only three studies under the topic of carbonaceous aerosols in Thailand collected at Phimai (central Thailand, Nakhon Ratchasima province), Hat-Yai city (southern region, Songkhla province) and Bangkok metropolitan [17-19]. Unfortunately, there is no peer-reviewed paper published in international journals regarding both the vertical distribution and diurnal variation of OC/EC compositions in Southern atmosphere of Thailand. Additionally, the impact of maritime aerosols on diurnal variation of carbonaceous aerosols in Southeast Asia has not been well investigated. Overall, the major aims of this research are to intensively evaluate the diurnal variations and vertical distributions of carbonaceous aerosols collected at the city center of Hat-Yai. Air samples were collected every three hours for three days at three different levels (i.e. Site 1: $30 \mathrm{~m}$; Site 2: $60 \mathrm{~m}$; Site 3: $125 \mathrm{~m}$ above the ground level) at Novotel Centara Hat-Yai Hotel (Site 1) and Lee Gardens Plaza Hotel (Site 2 and Site 3) in December $17^{\text {th }}-20^{\text {th }}, 2007$. Diurnal variation and vertical distribution of carbonaceous compositions in $\mathrm{PM}_{10}$ will be further discussed in detail. 


\section{Methodology}

\subsection{Sampling site descriptions and monitoring period}

It is well known that Hat-Yai is the largest metropolitan area in Southern part of Thailand with a population of 157,359 (2008) in the city itself, occupying an area of 7,393 square kilometers on the eastern side of the Malaysian Peninsula. HatYai is a business city located in the southern part of Thailand $\left(7^{\circ} 1{ }^{\prime} \mathrm{N} 100^{\circ} 28^{\prime} \mathrm{E}\right)$ adjacent to the Malaysian border, approximately $30 \mathrm{~km}$ away in the south of Gulf of Thailand. Hat-Yai is the largest city of Songkhla Province, the largest metropolitan area in Southern, and third largest metropolitan area of the country. Although the air quality levels in Hat-Yai are categorized as satisfactory in normal condition, the atmospheric concentrations of air pollutants exceeded the national air quality standard as a consequence of trans boundary pollution from uncontrollable forest fire in Indonesia. Hat-Yai city is categorized as tropical monsoon climate (Type Am) based on The Köppen climate classifications, with the 30 year average highest and lowest recorded temperature of $32.3^{\circ} \mathrm{C}\left(90.1^{\circ} \mathrm{F}\right)$ and $22.9^{\circ} \mathrm{C}\left(73.2^{\circ} \mathrm{F}\right)$ respectively. The 30 -year average precipitation was recorded as $134.5 \mathrm{~mm}$. Two observatory stations, namely Novotel Centara HatYai Hotel $\left(7^{\circ} 00^{\prime} 20.65^{\prime \prime} \mathrm{N} 100^{\circ} 28^{\prime} 15.65^{\prime \prime}\right.$ E) and Lee Gardens Plaza Hotel $\left(7^{\circ} 00^{\prime} 21.39^{\prime \prime} \mathrm{N} 100^{\circ} 28^{\prime} 15.94^{\prime \prime} \mathrm{E}\right)$, were located in the center of Hat-Yai city encompassed by schools, business buildings including cloth and snack shops in Kim Yong market. Since these hotels are located adjacent to each other, and both of them are situated at the city center, it appears reasonable to set the air quality observatory sites at these two locations. Furthermore, Lee Garden Plaza Hotel is the highest building in Hat-Yai city and thus it seems rationale to utilize these data set for diurnal variation analysis.

Three different measurement sites were prudently selected according to its elevation. Site 1 was placed at Novotel Centara Hat-Yai Hotel at $30 \mathrm{~m}$ above building basement, whilst Site 2 and Site 3 were positioned at Lee Gardens Grand Plaza Hotel at $60 \mathrm{~m}$ and $125 \mathrm{~m}$ above the ground level respectively. Intensive monitoring campaigns were performed at all measurement sites concurrently from December $17^{\text {th }}$ to $20^{\text {th }} 2007$ in winter. $\mathrm{PM}_{10}$ samples were collected every three hours consecutively from 21:00 h December $17^{\text {th }}$ to $21: 00 \mathrm{~h}$ December $20^{\text {th }}$ by using Graseby-Andersen High Volume Air Sampler. More detailed description of the air sampling method was provided in "Compendium Method IO 2.2. Sampling of Ambient Air for $\mathrm{PM}_{10}$ Using an Andersen Dichotomous Sampler".

\subsection{OC/EC analysis}

Procedures for OC/EC analysis including calibrations and QA/QC were conducted at the laboratory of the Department of Civil and Structural Engineering, Research Centre for Urban Environmental Technology and Management, The Hong Kong Polytechnic University, China. These procedures are essentially the same as described earlier by Cao et al. [23]. Generally, OC and $\mathrm{EC}$ were defined as sum of $\mathrm{OC}$ fractions and $\mathrm{EC}$ fractions $(\mathrm{OC} 1+\mathrm{OC} 2+$ 
$\mathrm{OC} 3+\mathrm{OC} 4)$ and $\mathrm{EC}$ fractions (EC1 + EC2 + EC3 + OP) individually, based on the IMPROVE TOR (Interagency Monitoring to Protect Visual Environments Thermal Optical Reflectance) protocol (Chow et al., [20, 21]; Fung et al. [22]). For more details, the quality control and quality assurance (QA/QC) have been discussed in Cao et al. [23].

\section{Results and discussion}

\subsection{Diurnal variation of $\mathrm{OC}$ and EC}

Diurnal variation of three-hourly $\mathrm{PM}_{10}, \mathrm{TC}, \mathrm{OC}$, and EC are displayed in Table 1 and Fig. 1 and represent monitoring period of three days. During this observation period, the correlation coefficients $(R)$ between OC and EC were highest at Site 1 $(R=0.80)$ followed by Site $2(R=0.60)$ and Site $3(R=0.070)$ respectively. The altitude-decreasing pattern of $R$ can be explained by numerous factors. Firstly, the photolysis and heterogeneous chemical reactions with trace gaseous species can be interpreted for this consequence. Since there were significant differences $(p<0.05)$ between solar radiation measured at Site $1\left(109.3 \pm 149.9 \mathrm{~W} \mathrm{~m}^{-2}\right) v s$. Site $2\left(98.7 \pm 115.9 \mathrm{~W} \mathrm{~m}^{-2}\right)$ and Site $2 v s$. Site $3\left(145.6 \pm 183.9 \mathrm{~W} \mathrm{~m}^{-2}\right)$, it would be safe to assume that photolysis activities play a major role in oxidizing carbonaceous aerosols and thus altering OC-EC correlations at higher altitude. Secondly, wind speed might influence the correlations between OC and EC due to the fluctuations in magnitude of dispersion occurred in different altitudes. The domination of westerly wind followed by southwesterly wind and westsouthwesterly wind at level-1 with the percentage contribution of $51 \%, 29 \%$ and $17 \%$ respectively. Interestingly, the easterly and east-southeasterly wind occupied the air mass observed at level- 2 with the percentage contribution of $47 \%$ and $44 \%$ in that order.

Unlike other two observatory sites, level-3 was influenced by air mass from all directions. Significant differences of wind speed $(p<0.001)$ found in Site $1\left(2.5 \pm 0.55 \mathrm{~m} \mathrm{~s}^{-1}\right) v s$. Site $2\left(3.5 \pm 0.94 \mathrm{~m} \mathrm{~s}^{-1}\right)$ and Site $2 v s$. Site $3(1.6 \pm$ $\left.0.46 \mathrm{~m} \mathrm{~s}^{-1}\right)$ support this idea. Thirdly, the strength of individual emission sources varied with wind direction. Hence, significant differences of wind direction $(p<$ $0.001)$ detected at Site $1\left(252 \pm 17^{\circ}\right) v s$. Site $2\left(100 \pm 11^{\circ}\right)$ and Site $2 v s$. Site 3 $\left(152 \pm 50^{\circ}\right)$ emphasize the importance of emission sources on variation of $R$ values. When an air mass is flowing across an emission source area around HatYai city, it can lead to emissions and subsequently higher emissions of atmospheric concentrations of carbonaceous aerosols. It is well known that wind direction plays a significant role on atmospheric concentrations of POPs [24, 25]. For instance, a four-fold increase in atmospheric PCBs over southern Lake Michigan when air masses were traveling from a vector between Evanston, IL, and Gary, IN has been reported by Simcik et al. [26]. A similar four-fold increase in atmospheric concentrations was observed for gas-phase phenanthrene over the northern Chesapeake Bay when winds blew from Baltimore [27]. As illustrated in Fig. 1, the maximum $\mathrm{OC}$ and EC concentrations were detected during the observation period of 21:00-00:00 on 17/12/2007 at Site 1 when HatYai city showed the highest vehicular density at these peak hours. 

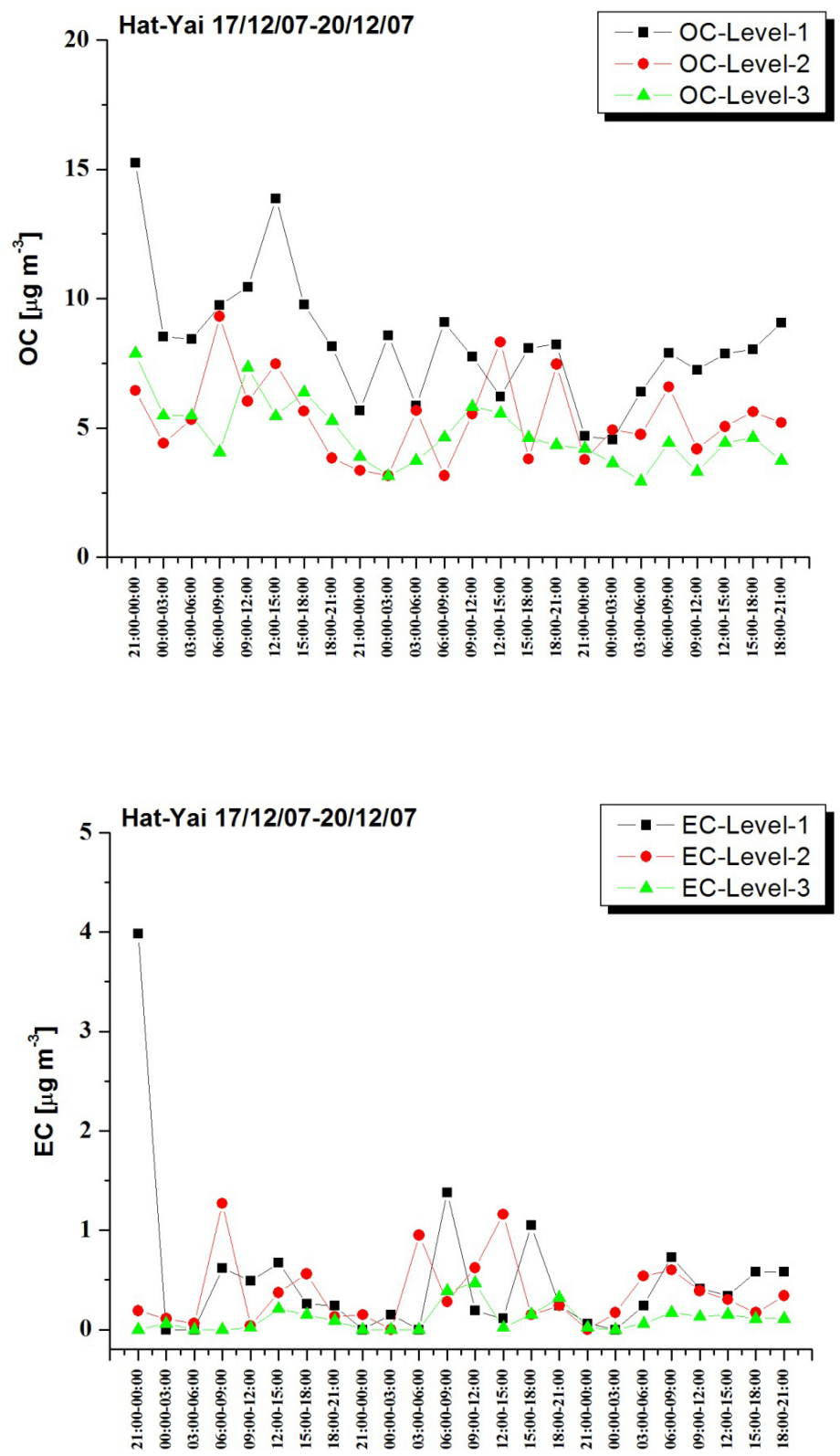

Figure 1: Diurnal variation of $\mathrm{OC}$ and $\mathrm{EC}$ in $\mathrm{PM}_{10}$ collected at Hat-Yai from $17 / 12 / 2007$ to $20 / 12 / 2007$. 
Since observatory sites are surrounded by restaurants and encompassed by night markets, it appears plausible to ascribe the highest content of carbonaceous aerosols from 21:00 to 00:00 as a mixture of traffic originated air pollutants. The overall declination of carbonaceous contents of all sampling sites was prominent after midnight of 17/12/2007. This can be explained by some small contributions of wet-depositions caused by irregular light shower rain occurred during the three days of monitoring campaign. The morning peak of $\mathrm{OC}$ and $\mathrm{EC}$ found during the sampling period of 06:00-09:00 reflected the crucial role of vehicular exhausts on carbonaceous contents in Hat-Yai city.

Table 1: Statistic description of concentrations of carbonaceous species and its percentage contribution in $\mathrm{PM}_{10}$ collected at Hat-Yai city.

\begin{tabular}{lcccc}
\hline Sampling Height $(\mathrm{m})$ & $\mathrm{PM}_{10}\left(\mu \mathrm{g} \mathrm{m}^{-3}\right)$ & $\mathrm{TC}\left(\mu \mathrm{g} \mathrm{m}^{-3}\right)$ & $\mathrm{OC}\left(\mu \mathrm{g} \mathrm{m}^{-3}\right)$ & $\mathrm{EC}\left(\mu \mathrm{g} \mathrm{m}^{-3}\right)$ \\
\hline Level-3 $(125 \mathrm{~m})$ & $46.6 \pm 14.1$ & $4.9 \pm 1.3$ & $4.8 \pm 1.3$ & $0.1 \pm 0.1$ \\
Level-2 $(60 \mathrm{~m})$ & $41.2 \pm 5.9$ & $5.7 \pm 1.9$ & $5.4 \pm 1.6$ & $0.4 \pm 0.3$ \\
Level-1 $(30 \mathrm{~m})$ & $42.5 \pm 11.0$ & $8.8 \pm 3.1$ & $8.3 \pm 2.5$ & $0.5 \pm 0.8$ \\
\hline
\end{tabular}

\subsection{OC/EC ratios}

Overall, the average OC/EC ratios observed in this study were $16.2 \pm 3.1,13.5 \pm$ 4.0 and $48.0 \pm 13.0$ for Site 1 , Site 2 and Site 3 respectively. Site 3 averaged OC/EC ratio was significantly three times higher than those of Site 1 and Site 2 with the confidence level of $95 \%$. The existence of extremely high OC/EC ratios observed in Hat-Yai city can be interpreted as a consequence of the relatively low EC background in the coastal atmosphere coupled with the formation of secondary organic aerosol (SOA) during the long range transport of maritime aerosols. Several studies have been ascribed the relatively high $\mathrm{OC} / \mathrm{EC}$ ratios as a consequence of the formation of SOA. For instance, it was estimated that SOA comprises for 30 to $80 \%$ of total OC collected at Southern and Central California [28]. However, one should bear in mind that several factors can significantly alter this ratio. Firstly, the differences in analytical techniques (i.e. Thermal Optical Transmittance vs. Thermal Optical Reflectance) can affect the predictions of OC/EC ratios [21]. Secondly, some positive and negative sampling artifacts can be caused by the selection of filter types (e.g. glass fiber filter or quartz fiber filter) as well as the employment of air samplers (e.g. high volume air sampler or denuded sampler). It is also worth to mention that biomass and agricultural residue burnings play a significant role in enhancing the OC/EC ratios as previously mentioned in several reports [18, 29]. Since Hat-Yai city is surrounded by numerous para-rubber sheet factories, it seems rationale to attribute the relatively high $\mathrm{OC} / \mathrm{EC}$ ratios as a result of emissions derived from biomass-fired utilities using during the manufacturing process. It is also crucial to stress that open burning of rice straw after harvesting is a common practice in Thailand and other Asian countries and thus to some extent enhance the OC/EC ratios. In addition, the relative high $\mathrm{OC} / \mathrm{EC}$ ratios detected at agricultural area of Korea, Kosan, support these interpretations. 


\subsection{Impact of aerosol types on variation of SOC}

Because of the geographic configuration of Hat-Yai city, which possesses more than $50 \%$ of the surface area adjacent to coastal lines, it is curious to investigate the impact of maritime aerosol on the variation of carbonaceous compositions. For decades, the chemical characteristics of water-soluble ionic species in aerosols have been intensively studied in various parts of the world. Despite of differences in both meteorological constraints and emission sources, several studies concluded that $\mathrm{Cl}^{-}$and $\mathrm{SO}_{4}{ }^{2-}$ are major contributors of WSIS mostly found in maritime aerosols whilst $\mathrm{K}^{+}$and $\mathrm{NH}_{4}^{+}$have tended to be the main compositions of those particles originated from biomass and agricultural waste burnings (Allen et al., [30]; Kocaka et al. [34]; Matsumoto et al. [35]; Osada et al. [36]; Park et al. [31]). Since particulate $\mathrm{NO}_{3}{ }^{-}$is a good indicator of those aerosols derived from traffic emissions and other imperfect combustions of fossil fuels, one can take advantage of binary ratios between maritime and biomass burning WSIS to traffic exhaust originated $\mathrm{NO}_{3}{ }^{-}$to classify aerosol types. In order to categorize various types of air masses, the ratios of $\mathrm{Cl}^{-} / \mathrm{NO}_{3}{ }^{-}, \mathrm{SO}_{4}{ }^{2-} / \mathrm{NO}_{3}{ }^{-}$, $\mathrm{K}^{+} / \mathrm{NO}_{3}{ }^{-}$and $\mathrm{NH}_{4}{ }^{+} / \mathrm{NO}_{3}{ }^{-}$were carefully employed by using the concept of outlier (i.e. the values lie beyond two standard deviations of the mean). For instance, those outliers of $\mathrm{Cl}^{-} / \mathrm{NO}_{3}{ }^{-}, \mathrm{SO}_{4}{ }^{2-} / \mathrm{NO}_{3}{ }^{-}, \mathrm{K}^{+} / \mathrm{NO}_{3}{ }^{-}$and $\mathrm{NH}_{4}{ }^{+} / \mathrm{NO}_{3}{ }^{-}$can be considered as represents of maritime aerosols, biomass burning and agricultural waste burning particles respectively.

Further estimation of secondary organic carbon in Hat-Yai $\mathrm{PM}_{10}$ was performed by using the concept of $\mathrm{Na}$ et al. [12]. The idea is based on the assumption that samples having the lowest OC/EC ratios contain almost exclusively primary carbonaceous compounds [32]. For this study, OC/EC ratios of 6.0, 6.8 and 12.6, (the average of the three lowest OC/EC ratios), were employed to estimate the secondary organic carbon (SOC) content of Hat-Yai $\mathrm{PM}_{10}$ at Site 1, Site 2 and Site 3 sampling sites respectively. The concentration of secondary organic carbon $\left(O C_{\mathrm{sec}}\right)$ can be estimated using the subsequent equation:

$$
O C_{s e c}=O C_{t o t}-E C \times(O C / E C)_{\text {primary }}
$$

where $(O C / E C)_{\text {primary }}$ is the average value of the three lowest $O C / E C$ ratios and $O C_{\text {tot }}$ is the total organic carbon. By employing Equation (1) to compute $O C_{\mathrm{sec}}$ contents in Hat-Yai $\mathrm{PM}_{10}$, the percentage contributions of $O C_{\mathrm{sec}}$ to $O C_{\text {tot }}$ were found to be $67.8 \pm 23.0 \%, 56.7 \pm 27.6 \%$ and $66.8 \pm 23.2 \%$ for Site 1 , Site 2 and Site 3 respectively. The total average value of $O C_{\mathrm{sec}}$ at all levels was $63.8 \pm$ $24.6 \%$. This average value is approximately 1.6 and 3.8 times higher than those observed in Kaohsiung (40.0\%) and Birmingham, UK (17\%) respectively but similar to those detected in Claremont, US $\mathrm{PM}_{2.5}(65 \%)$ [31-33].

As clearly illustrated in Table 2, the estimated percentage contributions of $O C_{\text {sec }}$ as categorized in maritime aerosol group by using the binary ratios of $\mathrm{Cl}^{-}$ $/ \mathrm{NO}_{3}{ }^{-}$and $\mathrm{SO}_{4}{ }^{2-} / \mathrm{NO}_{3}{ }^{-}$are approximately 1.44 times higher than those of nonemaritime aerosol group at the confidence level of $95 \%$. Correspondingly, 


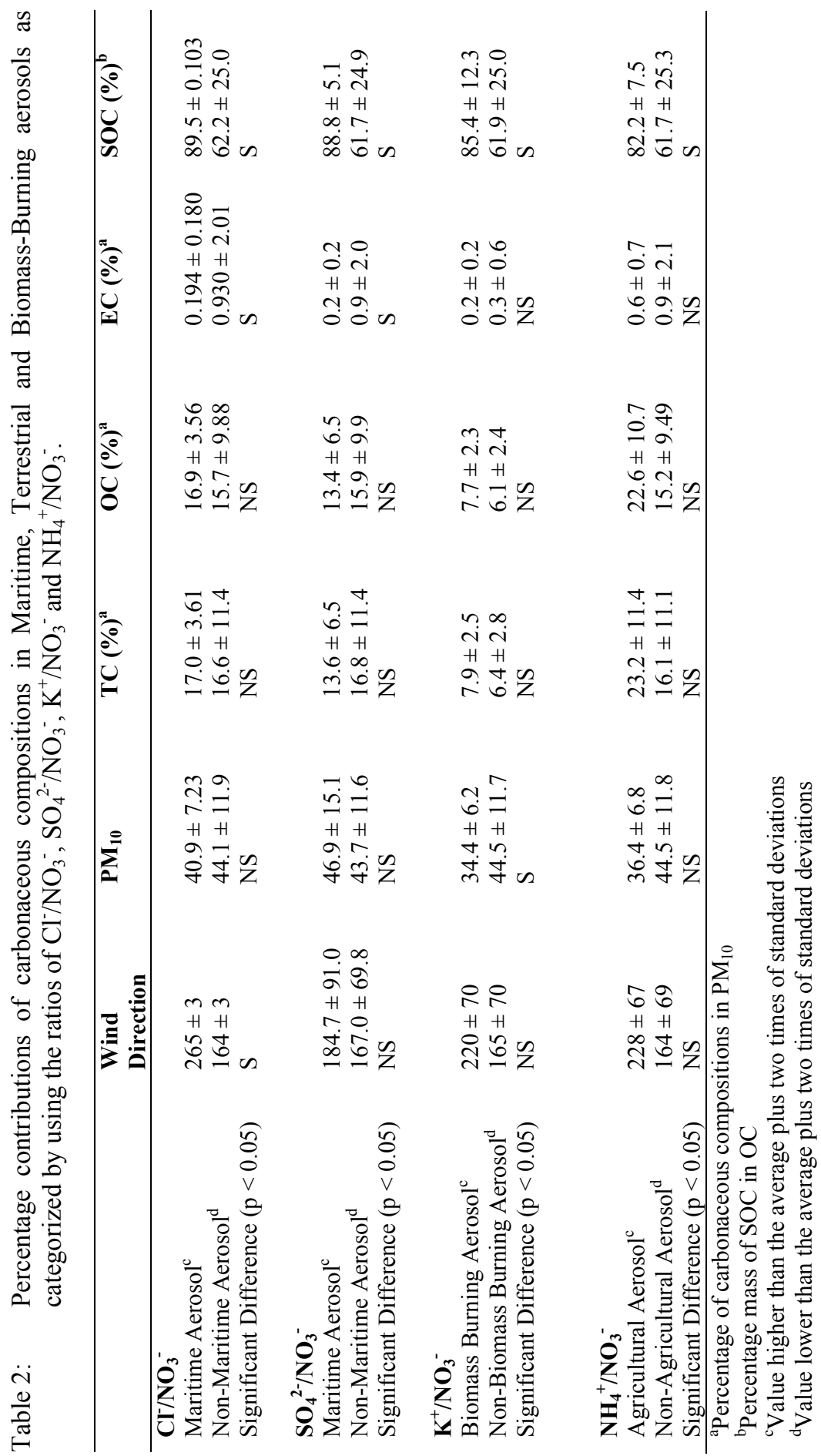


biomass burning originated aerosols as defined by the binary ratio of $\mathrm{K}^{+} / \mathrm{NO}_{3}{ }^{-}$is significantly 1.38 times higher than those of non-biomass burning group. In addition, the calculated percentage contribution of $O C_{\mathrm{sec}}$, which is classified in agricultural waste burning aerosol group by applying the binary ratios of $\mathrm{NH}_{4}{ }^{+} / \mathrm{NO}_{3}{ }^{-}$, is 1.33 times higher than those of non-agricultural waste burning group. Overall, this indicates the highly complicated mechanisms of SOC formation in the atmospheric environment of Hat-Yai city.

\section{Conclusions}

An important day-to-night difference in the magnitude of tourism activities might have explained the large discrepancy observed between daytime and nighttime of carbonaceous composition levels in $\mathrm{PM}_{10}$ samples during the monitoring period. Despite of its moderate level of OC and EC contents, Hat-Yai $\mathrm{PM}_{10}$ contains relatively high $\mathrm{OC} / \mathrm{EC}$ ratios indicating the strong influence of either aged particles derived from long-range transportation and/or biomass and agricultural waste burning aerosols. While traffic emissions play a major role in governing carbonaceous contents at ground level, wind speed and emission source type significantly influence OC and EC levels at higher altitudes. The concept of binary ratios using WSIS highlights the contribution of both maritime and biomass/agricultural waste burning aerosols on formation of SOC at the Southern coastal city of Thailand.

\section{Acknowledgements}

The authors thank Mashucon Public Co. Ltd., and School of Social and Environmental Development, National Institute of Development Administration for financial support.

\section{References}

[1] O'Brien, M.D., Mitchell M.R., 2003. Atmospheric heating due to carbonaceous aerosol in northern Australia - confidence limits based on TOMS aerosol index and sun-photometer data. Atmospheric Research 66 (1-2), 21-41.

[2] Shih, S.T., Lai, H.C., Hung, F.H., Ku, Y.S., Tsai, J.P., Yang, T., Liou, H.S., Loh, H.C., Jaakkola, K.J.J., 2008. Elemental and organic carbon exposure in highway tollbooths: A study of Taiwanese toll station workers. Science of the Total Environment 402 (2-3), 163-170.

[3] Repine, E.J., Reiss, K.O., Elkins, N., Chughtai, R.A., Smith M.D., 2008. Effects of fine carbonaceous particles containing high and low unpaired electron spin densities on lungs of female mice. Translational Research 152 (4), 185-193. 
[4] Dachs, J., Eisenreich, S.J., 2000. Adsorption onto aerosol soot carbon dominates gas-particle partitioning of polycyclic aromatic hydrocarbons. Environmental Science and Technology 34, 3690-3697.

[5] Pongpiachan, S., Choochuay, C., Hattayanone, M., Kositanont, C., 2013. Temporal and spatial distribution of particulate carcinogens and mutagens in Bangkok, Thailand. Asian Pacific Journal of Cancer Prevention 14(3), 1879-87.

[6] Pongpiachan, S., 2013. Vertical distribution and potential risk of particulate polycyclic aromatic hydrocarbons in high buildings of Bangkok, Thailand. Asian Pacific Journal of Cancer Prevention 14(3), 1865-77.

[7] Pongpiachan, S., 2013. Diurnal Variation, Vertical Distribution and Source Apportionment of Carcinogenic Polycyclic Aromatic Hydrocarbons (PAHs) in Chiang-Mai, Thailand. Asian Pacific Journal of Cancer Prevention 14(3), 1851-63.

[8] Pongpiachan, S., Ho, K.F., Cao, J. 2013. Estimation of Gas-Particle Partitioning Coefficients (Kp) of Carcinogenic Polycyclic Aromatic Hydrocarbons by Carbonaceous Aerosols Collected at Chiang-Mai, Bangkok and Hat-Yai, Thailand. Asian Pacific Journal of Cancer Prevention 14(4), 3369-84.

[9] Jones, C.K., Voogt D.P., 1999. Persistent organic pollutants (POPs): state of the science. Environmental Pollution 100 (1-3), 209-221.

[10] Cao, J.J., Lee, C.S., Ho, F.K., Zou, C.S., Fung, K., Li, Y., Watson, G.J., Chow C.J., 2004. Spatial and seasonal variations of atmospheric organic carbon and elemental carbon in Pearl River Delta Region, China. Atmospheric Environment 38 (27), 4447-4456.

[11] Han, M.Y., Han, W.Z., Cao, J.J., Chow, C.J., Watson, G.J., An, S.Z., Liu, X.S., Zhang J.R., 2008. Distribution and origin of carbonaceous aerosol over a rural high-mountain lake area, Northern China and its transport significance. Atmospheric Environment 42 (10), 2405-2414.

[12] Na, K., Sawant, A.A., Song, C., Cocker III R.D., 2004. Primary and secondary carbonaceous species in the atmosphere of Western Riverside County, California. Atmospheric Environment 38 (9), 1345-1355.

[13] Ram, K., Sarin, M.M., Hegde P., 2008. Atmospheric abundances of primary and secondary carbonaceous species at two high-altitude sites in India: Sources and temporal variability. Atmospheric Environment 42 (28), 6785-6796.

[14] Pio, C., Cerqueira, M., Harrison, M.R., Nunes, T., Mirante, F., Alves, C., Oliveira, C., Sanchez de la Campa, A.M., Artíñano, B., Matos M., 2011. $\mathrm{OC} / \mathrm{EC}$ ratio observations in Europe: Re-thinking the approach for apportionment between primary and secondary organic carbon. Atmospheric Environment 45 (34), 6121-6132.

[15] Yu, S., Dennis, L.R., Bhave, V.P., Eder K.B., 2004. Primary and secondary organic aerosols over the United States: estimates on the basis of observed organic carbon (OC) and elemental carbon (EC), and air 
quality modeled primary OC/EC ratios. Atmospheric Environment 38 (31), 5257-5268.

[16] Zeng, T., Wang Y., 2011. Nationwide summer peaks of OC/EC ratios in the contiguous United States. Atmospheric Environment 45 (3), 578-586.

[17] Li, C., Tsay, C.S., Hsu, C.N., Kim, Y.J., Howell, G.S., Huebert, J.B., Ji, Q., Jeong, J.M., Wang, H.S., Hansell, A.R., Bell W.S., 2012. Characteristics and composition of atmospheric aerosols in Phimai, central Thailand during BASE-ASIA. Atmospheric Environment 78, 60-71.

[18] Pongpiachan, S., Thamanu, K., Ho, K.F., Lee, S.C., Sompongchaiyakul P., 2009. Predictions of gas-particle partitioning coefficients (Kp) of polycyclic aromatic hydrocarbons at various occupational environments of Songkhla province, Thailand. The Southeast Asian Journal of Tropical Medicine and Public Health 40 (6), 1377-1394.

[19] Sahu, K.L., Kondo, Y., Miyazaki, Y., Pongkiatkul, P., Kim Oanh N.T., 2011. Seasonal and diurnal variations of black carbon and organic carbon aerosols in Bangkok. Journal of Geophysical Research 116, 1-14.

[20] Chow, J.C., Watson, J.G., Pritchett, L.C., Pierson, W.R., Frazier, C.A., Purcell R.G., 1993. The DRI thermal/optical reflectance carbon analysis system: Description, evaluation and applications in US air quality studies. Atmospheric Environment 27A (8), 1185-1201.

[21] Chow, J.C., Watson, J.G., Crow, D., Lowenthal, D.H., Merrifield T., 2001. Comparison of IMPROVE and NIOSH carbon measurements. Aerosol Science and Technology 34, 23-34.

[22] Fung, K.K., Chow, J.C., Watson J.G., 2002. Evaluation of OC/EC speciation by thermal manganese dioxide oxidation and the IMPROVE method. Journal of the Air \& Waste Management Association 52(11), 1333-1341.

[23] Cao, J.J., Lee, S.C., Ho, K.F., Zhang, X.Y., Zou, S.C., Fung, K., Chow, J.C., Watson J.G., 2003. Characteristics of carbonaceous aerosol in Pearl River delta region, China during 2001 winter period. Atmospheric Environment 37, 1451-1460.

[24] Pongpiachan S. (2006). Source apportionment of semi-volatile organic compounds in urban and rural air. PhD thesis, University of Birmingham, Birmingham.

[25] Pongpiachan, S., Surapipit, V., Ketratanakul, A., Wuttijak, N \& Pongnoppa, A. Risk analysis by emission source strengths and wind directions of trace gases at Map Ta Phut Industrial Estate, Rayong province, Thailand. Risk Analysis VII, WIT press, pp. 337-347. ISBN: 978-1-84564-472-7, ISSN (Online): 1743-3517, ISSN (Print): 1746-4463, September 2010.

[26] Simcik, M.F., Zhang, H., Eisenreich, S.J., Franz, T.P., 1997. Urban contamination of the Chicago/Coastal Lake Michigan atmosphere by PCBs and PAHs during AEOLOS. Environmental Science \& Technology 31(7), 2141-2147.

[27] Dachs, J., Glenn, T.R., Gigliotti, C.L., Brunciak, P., Totten, L.A., Nelson, E.D., Franz, T.P., Eisenreich, S.J., 2002. Process driving the short-term 
variability of polycyclic aromatic hydrocarbons in the Baltimore and northern Chesapeake Bay atmosphere, USA. Atmospheric Environment 36(14), 2281-2295.

[28] Schauer, J.J., Rogge, W.F., Hildemann, L.M., Mazurek, M.A., Cass, G.R., Simoneit, B.T., 1996. Source Apportionment of Airborne Particulate Matter Using Organic Compounds as Tracers. Atmospheric Environment 30, 3837-3855.

[29] Cao, J.J., Lee, S.C., Chow, J.C., Watson, J.G., Ho, K.F., Zhang, R.J., Jin, Z.D., Shen, Z.X., Chen, G.C., Kang, Y.M., Zou, S.C., Zhang, L.Z., Qi, S.H., Dai, M.H., Cheng, Y., Hu, K., 2007. Spatial and seasonal distributions of carbonaceous aerosols over China. Journal of Geophysical Research 112, D22S11. doi: 10.1029/2006JD008205.

[30] Allen, G.A., Cardoso, A.A., da Rocha, O.G., 2004. Influence of sugar cane burning on aerosol soluble ion composition in Southeastern Brazil. Atmospheric Environment 38, 5025-5038.

[31] Park, S.S., Cho, Y.S., 2011. Tracking sources and behaviors of watersoluble organic carbon in fine particulate matter measured at an urban site in Korea. Atmospheric Environment 45, 60-72.

[32] Castro, M.L., Pio, A.C., Harrison, M.R \& Smith, T.J.D., 1999. Carbonaceous aerosols in urban and rural European atmospheres: estimation of secondary organic carbon concentrations. Atmospheric Environment 33(17), 2771-2781.

[33] Lin, J.J., Tai, S.H., 2001. Concentrations and distributions of carbonaceous species in ambient particles in Kaohsiung City, Taiwan. Atmospheric Environment 35(15), 2627-2636.

[34] Kocaka, M., Mihalopoulosb, N \& Kubilay, N., 2007. Chemical composition of the fine and coarse fraction of aerosols in the northeastern Mediterranean. Atmospheric Environment 41, 7351-7368.

[35] Matsumoto K., Nagao, I., Tanaka, H., Miyaji, H., Iida, T \& Ikebe, Y., 1998. Seasonal characteristics of organic and inorganic species and their size distributions in atmospheric aerosols over the Northwest Pacific Ocean. Atmospheric Environment 32(11), 1931-1946.

[36] Osada, K., Kido, M., Nishita, C., Matsunaga, K., Iwasaka, Y., Nagatani, M \& Nakada, H., 2002. Changes in ionic constituents of free tropospheric aerosol particles obtained at Mt. Norikura (2770 m a.s.1.), central Japan, during the Shurin period in 2000. Atmospheric Environment 36, 54695477. 